https://www.journal-imab-bg.org

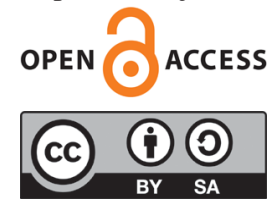

Original article

\title{
A SURVEY OF THE EXPERIENCE, KNOWLEDGE AND ATTITUDE OF DENTAL PRACTITIONERS IN BULGARIA ABOUT CHILD ABUSE AND NE- GLECT
}

\author{
Mariana M. Dimitrova, Veselina K. Kondeva, Sevda I. Rimalovska \\ Department of Pediatric Dentistry, Faculty of Dental Medicine, Medical Uni- \\ versity of Plovdiv, Bulgaria.
}

\begin{abstract}
:
Aim: To study the experience, knowledge and attitude of dental practitioners in Bulgaria about child abuse and neglect.

Material and methods: An anonymous questionnaire was conducted on 265 dental practitioners from several regions of Bulgaria. The questionnaire consists of 15 questions, including demographic characteristics and questions about their attitude, knowledge and actions in suspected cases of child abuse and neglect.

Results: Only $1 / 4$ of the respondents, $\mathrm{n}=60(22.3 \%)$, reported having suspected cases of Child Abuse and Neglect, and only $5.7 \%$ of them were reported to the authorities. The notification to the relevant institutions increases with the professional experience up to $30 \%$ to $40 \%$. The most common reason for not reporting was lack of knowledge of the way or procedures of reporting $(40.4 \%)$, fear of subsequent violence against the child $-23.4 \%$ and fear of consequences for the child when the relevant institutions interfere $-12.8 \%$. Irregular dental visits were considered the most significant indicator of neglect of children's oral health. Need for additional education and training on recognizing the signs of child abuse and neglect were reported from $72.5 \%$ of the participants.

Conclusions: The present study showed uncertainty in recognizing and reporting suspected cases of child abuse and neglect, especially for the younger dentists and for those without a certain specialty. There is a clear need for additional education of dental practitioners, as well as certain legal guidelines on the procedures of reporting and recording suspected cases, along with reliable support from the relevant institutions.
\end{abstract}

Keywords: child abuse, dental neglect, irregular dental visits,

\section{INTRODUCTION:}

According to the World Health Organization (WHO),"child abuse or maltreatment constitutes all forms of physical and/or emotional ill-treatment, sexual abuse, neglect or negligent treatment or commercial or other exploitation, resulting in actual or potential harm to the child's health, survival, development or dignity in the con- text of a relationship of responsibility, trust or power" [1]. Child abuse and neglect (CAN) is highly prevalent worldwide. Approximately $50-80 \%$ of all documented cases of child abuse involve the head and neck region (traumatisms of the mouth, head and face). Therefore, dental practitioners play a key role in detecting and diagnosing the physical and emotional manifestations of child abuse and reporting it to the competent authorities [2,3]. However, there is a lot of evidence that dental practitioners feel unprepared or inadequately informed to take on such a role and often are unsure about the procedure and the consequences if they suspect and report that a child has been abused [4,5].

Dental neglect is a form of child maltreatment and is defined by the British Society of Paediatric Dentistry as "the persistent failure to meet a child's basic oral health needs, likely to result in the serious impairment of a child's oral or general health or development" [6]. Dental neglect has a strong negative impact on a child's well-being, not only in childhood but also later in life. Detection of this problem is important for the physical and psychological health of children. Dental neglect is often misdiagnosed. Cavities, periodontal disease, and other oral conditions are commonly associated with inadequate attention to nutrition and dental hygiene and can be signs of neglect. These conditions can lead to pain, infection, loss of function and other health conditions, which can negatively affect the normal growth and development of a child [7]. Dentists should be able to determine whether the parent or caregiver understands the explanation and implications of the dental issue and, despite having the resources to address the condition, fails to do so.

Research has shown that parents/guardians, who abuse their children typically, change their child's physician frequently but are more likely to continue to visit the child's dentist, which gives dental professionals the opportunity to be the first to recognize and report suspected cases of child maltreatment [8]. Although dentists are capable of recognizing and suspecting cases of CAN, there is a lack of knowledge about how to proceed in such cases, and therefore much cases of child neglect are under-reported and never come to the attention of the authorities [9].There are different reasons for dentists' hesitancy to report suspected cases - lack of knowledge in referral proce- 
dure, consequences to the child, concerns about confidentiality, effect on work and fear of litigation and etc.[10].The purpose of this study was to assess the knowledge and attitudes among Bulgarian dental professionals to child abuse and neglect (CAN) and the reasons for not reporting suspected cases in relation to their professional experience and specialty.

\section{MATERIALS AND METHODS:}

An anonymous questionnaire was conducted on 265 dental practitioners from several regions of Bulgaria. Data was collected for a time period of 6 months from October 2018 to April 2019 on scientific meetings throughout the country. The questionnaire consists of multiple choice questions including demographic characteristics - gender, age, professional experience, specialty, and questions about their attitude, knowledge and actions in cases suspected of child abuse and neglect in their practice.

Data received were coded and analyzed using the Statistical Package for Social Sciences (IBM SPSS) software. For the presentation of the results were used descriptive analysis, Chi-square tests, one-step logistic regression analysis, multiple response and graphic analysis and a value of $\mathrm{p}<0.05$ was considered statistically significant.

\section{RESULTS:}

Of the surveyed dental practitioners $(n=265), 170$ $(64.20 \%)$ were females and $95(35.80 \%)$ males. Table 1 presents the distribution of the participants by age. The largest was the relative share of dental practitioners above 50 years of age $-123(46.40 \%)$.

Table 1. Distribution of the participants by age

\begin{tabular}{|l|c|c|}
\hline Age & N & $\%$ \\
\hline$<30$ years & 37 & 14 \\
\hline 31 y. -39 y. & 55 & 20,8 \\
\hline 40 y. 50 y. & 50 & 18,9 \\
\hline$>50$ years & 123 & 46,4 \\
\hline Total & 265 & 100 \\
\hline
\end{tabular}

The specialty and professional experience of the surveyed is presented in Table 2. Most of the respondents reported practicing dentistry for more than 20 years, and the majority were without a specific specialty.
Table 2. Distribution of the respondents according to the specialty and professional experience

\begin{tabular}{|l|l|c|c|}
\hline \multicolumn{2}{|c|}{} & $\mathbf{N}$ & $\%$ \\
\hline \multirow{4}{*}{ Specialty } & None & 99 & 37,4 \\
\cline { 2 - 4 } & General dentistry & 95 & 35,8 \\
\cline { 2 - 4 } & Pediatricdentistry & 30 & 11,3 \\
\cline { 2 - 4 } & Other & 41 & 15,5 \\
\cline { 2 - 4 } & Total & 265 & 100 \\
\hline \multirow{5}{*}{ Experience } & $<6$ years & 37 & 14 \\
\cline { 2 - 4 } & 6 y.-10 y. & 25 & 9,4 \\
\cline { 2 - 4 } & 11 y.-20 y. & 55 & 20,8 \\
\cline { 2 - 4 } & $>20$ y. & 148 & 55,8 \\
\cline { 2 - 4 } & Total & 265 & 100 \\
\hline
\end{tabular}

Only $1 / 4$ of the respondents, $n=60(22.3 \%)$, reported having suspected cases of CAN (Child Abuse and Neglect), and only $5.7 \%$ of them had reported the case to the authorities. None of the respondents with professional experience of less than 6 years informed the authorities about suspected cases of child abuse and neglect. With the increase of years of practical experience, we found a clear tendency for progression of the frequency of notifications to the relevant institutions, as $30 \%$ to $40 \%$ of the respondents with longer experience had reported such cases. The relationship between the indicators was found statistically significant at a $90 \%$ pobability of the results (Likelihood Ratio = $6,713, \mathrm{p}=0,082)$. The largest share of respondents who reported that they had patients victims of abuse and neglect were dentists with a specialty in "General Dentistry", followed by respondents without a specialty, i.e. a total of $74.6 \%$ of suspected cases of violence against children were reported by dentists without a specific specialty. The difference between the specialists and the frequency of reporting cases of CAN to the relevant institutions was not found statistically significant ( $\mathrm{p}=0,823$ ).

Table 3 presents some of the possible reasons for not reporting these suspected CAN cases. The most common reason not to notify the relevant authorities/institutions forCAN cases was "Lack of knowledge of the way or procedures of reporting" (40.4\%). Almost half of the surveyed reported a lackof information on how the relevant authorities can be notified. When combining the percentages of respondents who were "Unsure in the diagnosis of CAN" $(14.9 \%)$ with those who did not know the way of reporting, a very high relative share of respondents is formed $(55.3 \%)$. The second most common reason for not notifying authorities and institutions was "Fear of subsequent violence against the child" (23.4\%), followed by "Fear of consequences for the child when the relevant institutions interfere" $(12.8 \%)$. 
Table 3. Reasons for not reporting the suspected CAN cases

\begin{tabular}{|l|c|c|c|c|}
\hline & Frequency & Percent & $\begin{array}{c}\text { Valid } \\
\text { Percent }\end{array}$ & $\begin{array}{c}\text { Cumulative } \\
\text { Percent }\end{array}$ \\
\hline Fear of subsequent violence against the child & 11 & 4,2 & 23,4 & 23,4 \\
\hline Fear of aggression against the dentist & 3 & 1,1 & 6,4 & 29,8 \\
\hline Fearof a subsequent trial & 1 & 0,4 & 2,1 & 31,9 \\
\hline $\begin{array}{l}\text { Fear of consequences for the child when the relevant in } \\
\text { stitutions in terfere }\end{array}$ & 6 & 2,3 & 12,8 & 44,7 \\
\hline Lackofknowledgeofthewayorprocedureofreporting & 19 & 7,2 & 40,4 & 85,1 \\
\hline Unsureaboutthediagnosis & 7 & 2,6 & 14,9 & 100 \\
\hline Total & 47 & 17,7 & 100 & \\
\hline
\end{tabular}

The analysis of the results in relation to the professional experience of the respondents showed that for those with practice more than 20 years, the most important reasons for not reporting to the authorities were the "Fear of subsequent violence against the child" (63.6\%) and "Fear of consequences for the child when the relevant institutions interfere" $(50,0 \%)$. For the youngest respondents, the mostimportant were "Fear of consequences for the child when the relevant institutions interfere" (33.3\%) and "Lack of knowledge of the way or procedure of reporting" $(21.1 \%)$.

In relation to the presence of specific specialty and reasons for not informing the authorities for suspected of CAN cases, we found that for $66.7 \%$ of the dentists without specialty, the "Fear of aggression against the dentist" is the most important reason. Specialists in General Den- tistry most often reported "Fear of subsequent violence against the child" (63.6\%). "Lack of knowledge of the way or procedure of reporting" was most prevalent for Pediatric Dentists and those with another specialty. Table 4 presents the correlation between the professional experience of the respondents and their answers to the question "Do you consider that you are adequately informed about the recognition of the signs of Child Abuse and $\mathrm{Ne}$ glect?". The majority of the respondents $(57.8 \%)$ reported that they are not adequately informed about the recognition of the signs of child abuse and neglect. The least informed were the practitioners with professional experience from 6 to 10 years $(75.0 \%)$, but the differences were not found statistically significant (Pearson Chi-Square=5,606, $\mathrm{p}=0,132$ ).

Table 4. Answers to the question "Do you consider that you are adequately informed about the recognition of the signs of child abuse and neglect?" in relation to professional experience

\begin{tabular}{|l|c|c|c|c|}
\hline \multirow{2}{*}{$<6$ years } & & No & Yes & Total \\
\hline \multirow{2}{*}{6 y.-10y. } & $\mathrm{N}$ & 21 & 14 & 35 \\
\cline { 2 - 5 } & $\%$ & $60,00 \%$ & $40,00 \%$ & $100,00 \%$ \\
\hline \multirow{2}{*}{11 y.- 20 y. } & $\mathrm{N}$ & 18 & 6 & 24 \\
\cline { 2 - 5 } & $\%$ & $75,00 \%$ & $25,00 \%$ & $100,00 \%$ \\
\hline \multirow{3}{*}{$>20$ years } & $\mathrm{N}$ & 32 & 18 & 50 \\
\cline { 2 - 5 } & $\%$ & $52,10 \%$ & $47,90 \%$ & $100,000 \%$ \\
\hline \multirow{2}{*}{ Total } & $\mathrm{N}$ & 144 & 105 & 249 \\
\cline { 2 - 5 } & $\%$ & $57,80 \%$ & $42,20 \%$ & $100,00 \%$ \\
\hline
\end{tabular}

We found a positive correlation between the presence of specialty of the surveyed and their information about recognition of the signs of CAN. As shown in Table 5 , the most informed were the specialists in Pediatric Dentistry $(75.9 \%)$, and as least informed were the respondents without specialty - only $34.0 \%$ consider themselves as adequately prepared to recognize the signs of child abuse and neglect (Pearson Chi-Square $=16,418, \mathrm{p}=0,001$ ). 
Table 5. Answers to the question: "Do you consider that you are adequately informed about the recognition of the signs of child abuse and neglect?" in relation to specialty

\begin{tabular}{|l|c|c|c|c|}
\hline \multirow{2}{*}{ None } & $\mathrm{N}$ & 62 & 32 & 94 \\
\cline { 2 - 5 } & $\%$ & $66,00 \%$ & $34,00 \%$ & $100,00 \%$ \\
\hline \multirow{3}{*}{ General dentistry } & $\mathrm{N}$ & 53 & 34 & 87 \\
\cline { 2 - 5 } & $\%$ & $60,90 \%$ & $39,10 \%$ & $100,00 \%$ \\
\hline \multirow{3}{*}{ Pediatric Dentistry } & $\mathrm{N}$ & 7 & 22 & 29 \\
\cline { 2 - 5 } & $\%$ & $24,10 \%$ & $75,90 \%$ & $100,00 \%$ \\
\hline \multirow{2}{*}{ Other specialties } & $\mathrm{N}$ & 22 & 17 & 39 \\
\cline { 2 - 5 } & $\%$ & $56,40 \%$ & $43,60 \%$ & $100,00 \%$ \\
\hline \multirow{2}{*}{ Total } & $\mathrm{N}$ & 144 & 105 & 249 \\
\cline { 2 - 5 } & $\%$ & $57,80 \%$ & $42,20 \%$ & $100,00 \%$ \\
\hline
\end{tabular}

Need for additional education aimed at training on recognizing the signs of child abuse and neglect were reported from $72.5 \%$ of the participants. Such a necessity was especially important for the youngest respondents - $88.2 \%$ from the surveyed under the age of 30 years. Although significantly lower, additional education was needed for more than half of the dentists above the age of 50 years $(67.8 \%)$, $(p=0,006)$. Professional experience and specialty were not found significant in correlation to the need for additional training and education on recognizing signs of CAN ( $>0.05)$.

Dental professionals were also asked to choose the type of institution or person that they would inform in case of CAN in their practice. Table 6 presents the results in relation to the specialty and the professional experience of the surveyed.

Table 6. Answers to the question: "To whom would you address in case of doubt of CAN?

\begin{tabular}{|l|l|c|c|c|}
\hline \multirow{5}{*}{ Specialty } & None & $\begin{array}{c}\text { Child protection } \\
\text { service }\end{array}$ & $\begin{array}{c}\text { To a senior } \\
\text { colleague }\end{array}$ & $\begin{array}{c}\text { To the parent } \\
\text { or caregiver }\end{array}$ \\
\hline \multirow{5}{*}{ Experience } & General dentistry & $33.3 \%$ & $43.3 \%$ & $62.2 \%$ \\
\cline { 2 - 5 } & Pediatric dentistry & $36.6 \%$ & $31.7 \%$ & $16.2 \%$ \\
\cline { 2 - 5 } & Other & $14.6 \%$ & $10.0 \%$ & $5.4 \%$ \\
\hline \multirow{5}{*}{} & $<6$ years & $15.4 \%$ & $15.0 \%$ & $16.2 \%$ \\
\cline { 2 - 5 } & 6 y.-10 y. & $12.2 \%$ & $18.3 \%$ & $18.9 \%$ \\
\cline { 2 - 5 } & $11 \mathrm{y}-20 \mathrm{y}$. & $20.3 \%$ & $8.3 \%$ & $10.8 \%$ \\
\cline { 2 - 5 } & $>20 \mathrm{y}$. & $57.7 \%$ & $45.0 \%$ & $29.7 \%$ \\
\hline
\end{tabular}

The surveyed dentists also had to indicate whether, after identifying and explaining the child's dental problems and offering adequate treatment, indicators such as: irregular dental visits, inability to complete dental treatment or frequent dental visits with complaints from pain and in- fection, would increase their attention to possible child dental neglect. Table 7 and Table 8 are presented the answers in relation to the professional experience and specialty of the respondents and the indicators for child dental neglect.

Table 7. Correlation between professional experience and indicators for dental neglect

\begin{tabular}{|l|l|r|r|r|r|r|r|}
\hline \multicolumn{2}{|c|}{} & $<6$ years & 6 y.-10 y. & 11 y.- 20 y. & $>20$ years. & \multicolumn{1}{c|}{ Total } & $p$ \\
\hline \multirow{4}{*}{$\begin{array}{l}\text { Irregular dental } \\
\text { visits }\end{array}$} & Count & 22 & 16 & 35 & 104 & 177 \\
\cline { 2 - 7 } & $\%$ & $12,40 \%$ & $9,00 \%$ & $19,80 \%$ & $58,80 \%$ & $100,00 \%$ \\
\cline { 2 - 7 } & $\begin{array}{l}\% \text { within } \\
\text { Experience }\end{array}$ & $62,90 \%$ & $66,70 \%$ & $68,60 \%$ & $72,70 \%$ & $70,00 \%$ & \\
\hline
\end{tabular}




\begin{tabular}{|l|l|r|r|r|r|r|r|}
\hline \multirow{2}{*}{$\begin{array}{l}\text { Inability to } \\
\text { complete treatment }\end{array}$} & Count & 17 & 15 & 24 & 65 & 121 & \\
\cline { 2 - 6 } & $\%$ & $14,00 \%$ & $12,40 \%$ & $19,80 \%$ & $53,70 \%$ & $100,00 \%$ & \multirow{2}{*}{0,491} \\
\cline { 2 - 7 } & $\begin{array}{l}\% \text { within } \\
\text { Experience }\end{array}$ & $48,60 \%$ & $62,50 \%$ & $47,10 \%$ & $45,50 \%$ & $47,80 \%$ & \\
\hline \multirow{2}{*}{$\begin{array}{l}\text { Frequent dental visits } \\
\text { with complaints from } \\
\text { pain and infection }\end{array}$} & Count & 12 & 3 & 12 & 19 & 46 & \multirow{2}{*}{0,019} \\
\cline { 2 - 7 } & $\begin{array}{l}\% \text { within } \\
\text { Experience }\end{array}$ & $34,30 \%$ & $12,50 \%$ & $23,50 \%$ & $13,30 \%$ & $18,20 \%$ & \\
\hline \multirow{2}{*}{ Total } & $\begin{array}{l}\% \text { within } \\
\text { Experience }\end{array}$ & $100,00 \%$ & $100,00 \%$ & $100,00 \%$ & $100,00 \%$ & $100,00 \%$ & \\
\hline
\end{tabular}

Table 8. Correlation between specialty and indicators for dental neglect

\begin{tabular}{|c|c|c|c|c|c|c|c|}
\hline & & None & $\begin{array}{l}\text { General } \\
\text { Dentistry }\end{array}$ & $\begin{array}{l}\text { Pediatric } \\
\text { Dentistry }\end{array}$ & $\begin{array}{c}\text { Other } \\
\text { Specialty }\end{array}$ & Total & $\mathrm{p}$ \\
\hline \multirow{3}{*}{ Irregular dental visits } & Count & 74 & 58 & 20 & 25 & 177 & \multirow{3}{*}{0,364} \\
\hline & $\%$ & $41,80 \%$ & $32,80 \%$ & $11,30 \%$ & $14,10 \%$ & $100,00 \%$ & \\
\hline & $\begin{array}{l}\% \text { within } \\
\text { Specialty }\end{array}$ & $76,30 \%$ & $65,90 \%$ & $69,00 \%$ & $64,10 \%$ & $70,00 \%$ & \\
\hline \multirow{3}{*}{$\begin{array}{l}\text { Inability to } \\
\text { complete treatment }\end{array}$} & Count & 47 & 38 & 18 & 18 & 121 & \multirow{3}{*}{0,365} \\
\hline & $\%$ & $38,80 \%$ & $31,40 \%$ & $14,90 \%$ & $14,90 \%$ & $100,00 \%$ & \\
\hline & $\begin{array}{l}\% \text { within } \\
\text { Specialty }\end{array}$ & $48,50 \%$ & $43,20 \%$ & $62,10 \%$ & $46,20 \%$ & $47,80 \%$ & \\
\hline \multirow{3}{*}{$\begin{array}{l}\text { Frequent dental visits } \\
\text { with complaints from } \\
\text { pain and infection }\end{array}$} & Count & 16 & 15 & 6 & 9 & 46 & \multirow{3}{*}{0,798} \\
\hline & $\%$ & $34,80 \%$ & $32,60 \%$ & $13,00 \%$ & $19,60 \%$ & $100,00 \%$ & \\
\hline & $\begin{array}{l}\% \text { within } \\
\text { Specialty }\end{array}$ & $16,50 \%$ & $17,00 \%$ & $20,70 \%$ & $23,10 \%$ & $18,20 \%$ & \\
\hline Total & $\begin{array}{l}\% \text { within } \\
\text { Specialty }\end{array}$ & $100,00 \%$ & $100,00 \%$ & $100,00 \%$ & $100,00 \%$ & $100,00 \%$ & \\
\hline
\end{tabular}

\section{DISCUSSION:}

The majority of the dental practitioners included in this study reported that they were able to recognize signs of child abuse and neglect, but only a smallpart of the caseswasactually reported. Our results were similar to other studies, which also found that the reporting rates are very low in comparison with the number of suspected cases $[11,12,13]$. Almost half of the surveyed in our study reported a lackof information on how the relevant authorities can be notified for suspected of CAN cases. In other studies, uncertainty in the diagnosis was the factor perceived as most likely to prevent those referring $[11,14]$. The same factor was most cited by Scottish dentists [4]. "Fear of subsequent violence against the child" and "Fear of consequences for the child when the relevant institutions interfere" in our study were found as important reasons for not reporting to the authorities for the practitioners with practice more than 20 years which is reported from other authors as well $[12,13]$.

The European Union mandated that workers who are in close contact with children must report suspected abuse cases to the responsible legal authorities in their countries (child protection agencies or police). Some countries allow civilians to report such cases to the authorities, but without any legal obligation [15]. In our study, the majority of the dental practitioners with more than 20 years of work experience were more likely to inform the Child Protection Services or discuss the case with a colleague. The non-specialists were more likely to talk to the parent or caregiver. A similar study conducted in Saudi Arabia in 2014 found that discussing the case with the child's parents, discussing the case with a colleague, and documenting the signs and symptoms of abuse in the child's file were the most common actions taken by dentists when they suspected a case of abuse [13].

Child dental neglect is an important topic for dental practitioners as it may be the first sign of general neglect [16]. Diagnosing dental neglect can be a chalenge and that uncertainty in the diagnosis often results in low rates of reported cases. According to a systematic review of Bhatia SK, et al., 2014 as evidence for identifying the features of oral neglect are considered:

- failure to seek or delay seeking dental treatment - failure to comply with or complete treatment 
- failure to provide basic oral care

- impacts of dental disease such as pain, crying, stopping playing, disturbed sleep, difficulty in eating or change in food preferences, absence from school, repeated antibiotics, dental general anaesthesia, lower bodyweight, growth and quality of life, poor dental appearance, local infection, severe infection [17].

Identifying dental neglect is problematic because tooth decay in children is a common problem and does not necessarily mean that the child is at serious risk of physical or emotional harm. Dental professionals are advised to use their clinical judgement to assess each case individually in the context of the child's medical history and developmental stage, as well as factors such as access to dental treatment. Unfortunately, it is difficult to estimate the exact indicators of dental neglect. Signs that raise suspicion of this condition can be included in three groups: oral manifestations and clinical history of the child, social determinants of the child, parental characteristics [18, 19].

The American Academy of Pediatric Dentistry defines dental neglect as the "willful failure of parent or guardian to seek and follow through with treatment necessary to ensure a level of oral health essential for adequate function and freedom from pain and infection" [20].Indicators of dental neglect include:multiple, untreated caries easily detectable by a lay person; untreated pain, infection, bleeding, or trauma affecting the orofacial region;history or lack of continuity of care in the presence of identified dental pathology [21].

In our study, we aimed to estimate if indicators such as: irregular dental visits, inability to complete dental treatment, or frequent dental visits with complaints from pain and infection would increase the attention of the dental practitioners to a possible child dental neglect. Accord- ing to the results, irregular dental visits were considered the most significant indicator of neglect of children's oral health for the majority of the surveyed participants, with no statistical difference in relation to their practical experience and the type of specialty. This indicator was found important, especially for those with a practical experience of more than 20 years and for non-specialists. For more than half of the specialists in Pediatric dentistry $(62.1 \%)$, the inability to complete treatment was also an important indicator for child dental neglect. Frequent dental visits with complaints from pain and infection were considered as significant indicators for dental neglect from dental practitioners with more than 20 years of work experience.

\section{CONCLUSIONS:}

The practical experience and the specialty of the dental practitioners are factors that could influence the possibilities for identification and recognition of the signs of child abuse and neglect. Our study showed a lack of knowledge and uncertainty in recognizing and low rate of reporting suspected cases of child abuse and neglect, especially for the younger dentists and for those without certain specialty. Bulgarian dental practitioners expressed the need for guidelines along with additional education, training and support from the relevant governmental institutions on this issue.

\section{Abbreviations: \\ CAN - child abuse and neglect,}

\section{Acknowledgements:}

We gratefully acknowledge the contribution of the participants for performing this study.

\section{REFERENCES:}

1. Report of the Consultation on Child Abuse Prevention, 29-31 March 1999, WHO, Geneva. World Health Organization. [Internet]

2. Harris JC, Elcock C, Sidebotham PD, Welbury RR. Safeguarding children in dentistry: 1. Child protection training, experience and practice of dental professionals with an interest in paediatric dentistry. BrDent J. 2009 Apr 25;206(8):409-14. [PubMed]

3. Harris JC, Elcock C, Sidebotham PD, Welbury RR. Safeguarding children in dentistry: 2. Do paediatric dentists neglect child dental neglect? $\mathrm{Br}$ Dent J. 2009 May 9;206(9):465-70. [PubMed]

4. Cairns AM, Mok JY, Welbury RR. The dental practitioner and child protection in Scotland. Br Dent J. 2005 Oct 22;199(8):517-20. [PubMed]
5. Welbury RR, MacAskill SG, Murphy JM, Evans DJ, Weightman KE, Jackson MC, et al. General dental practitioners' perception of their role within child protection: a qualitative study. Eur J Paediatr Dent. 2003 Jun;4(2): 89-95. [PubMed]

6. Harris JC, Balmer RC, Sidebotham PD. British Society of Paediatric Dentistry: a policy document on dental neglect in children. Int $J$ Paed Dent. 2009May 14. [PubMed]

7.Fisher-Owens SA, Lukefahr JL, Tate AR. Oral and Dental Aspects of Child Abuse and Neglect. Pediatr Dent. 2017 Jul 15;39(4):278-283. [PubMed]

8. Thomas JE, Straffon L, Inglehart MR, Habil P. Knowledge and professional experiences concerning child abuse: An analysis of provider and stu- dent responses. Pediatric Dentistry. 2006 Sep-Oct;28(5):438-44.[PubMed]

9. Cawson P, Wattam C, Brooker S, Kelly G. Childmal treatment in the United Kingdom: a study of the prevalence of child abuse and neglect. NSPCC. November 1, 2000. [Internet]

10. Soumya Mohanan TV, Sankeshwari RM, Ankola AV. Perspectives towards child abuse and neglect among dental practitioners in Belagavicity: A cross-sectional study. $J E d u$ Health Promot. 2020 Nov 26; 9:295.[PubMed]

11. Chadwick BL, Davies J, Bhatia SK, Rooney C, McCusker N. Child protection: Training and experiences of dental therapists. BrDent J. 2009 Aug 8;207(3):E6. [PubMed]

12. Sonbol HN, Abu-Ghazaleh S, Rajab LD, Baqain ZH, Saman R, Al- 
Bitar ZB. Knowledge, educational experiences and attitudes towards child abuse amongst Jordanian dentists. Eur J DentEduc. 2012Feb;16(1): e158-65. [PubMed]

13. Al-Dabaan R, Newton JT, Asimakopoulou K. Knowledge, attitudes, and experience of dentists living in Saudi Arabia towards child abuse and neglect. Saudi Dent J. 2014 Jul;26(3):79-87. [PubMed]

14. Laud A, Gizani S, Maragkou S, Welbury R, Papagiannoulis L. Child protection training, experience, and personal views of dentists in the prefecture of Attica, Greece. Int J Paediatr Dent. 2013 Jan;23(1):64-71. [PubMed]

15. Katner DR, Brown CE. Mandatory reporting of oral injuries in dicating possible child abuse. J Am Dent Assoc. 2012 Oct;143(10):108792. [PubMed]

16. Souster G, Innes N. Some clarification of trigger signs for dental neglect. Evid Based Dent. 2014 Mar; 15(1):2-3. [PubMed]

17. Bhatia SK, Maguire SA, Chadwick BL, Hunter ML, Harris JC, Tempest V, et al. Characteristics of child dental neglect: a systematic review. J Dent. 2014 Mar;42(3):229-39. [PubMed]

18. Bradbury-Jones C, Innes $\mathrm{N}$, Evans D, Ballantyne F, Taylor J. Dentalneglectas a marker of broader neglect: a qualitative investigation of public health nurses' assessments of oral health in preschool children. $B M C$ Public Health. 2013Apr 19;13:370. [PubMed]

19. Tilvawala D, Murray C, Farah R, Broadbent JM. New Zealand dental the rapists' beliefs regarding child maltreatment. Aust N Z J Public Health. 2014Oct;38(5):480-4. [PubMed]

20. American Academy of Pediatric Dentistry. Definition of dental neglect. The Reference Manual of Pediatric Dentistry. Chicago, III.: AAPD. 2020:16. [Internet]

21. Vadiakas G, Roberts MW, Dilley DC. Child abuse and neglect: ethical and legal issues for dentistry. J Mass Dent Soc. 1991 Winter; 40(1): 13-5. [PubMed]

Please cite this article as: Dimitrova MM, Kondeva VK, Rimalovska SI. A survey of the experience, knowledge and attitude of dental practitioners in Bulgaria about child abuse and neglect. $J$ of IMAB. 2021 Oct-Dec;27(4):4113-4119. DOI: https://doi.org/10.5272/jimab.2021274.4113

Received: 10/09/2021; Published online: 25/11/2021

Address for correspondence:

Sevda Rimalovska,

Department of Pediatric Dentistry, Faculty of Dental Medicine, Medical University of Plovdiv,

3, Hristo Botev Blvd., 4000 Plovdiv, Bulgaria.

E-mail: dr.rimalovska@hotmail.com 